\title{
Study of Portal Hemodynamic Changes Using Doppler Ultrasound in Egyptian Cirrhotic Patients with Oesophageal Varices Treated By Band Ligation with or Without Beta Blockers
}

Portal Hemodynamics In Egyptian Cirrhotics

\author{
Authors \\ Mohamed Tamer Afifi ${ }^{1}$, Ezzat Ali Ahmed ${ }^{\mathbf{1}}$, Ayman Mohamed Shamseya ${ }^{1}$, Mohamed \\ Mahmoud Elshafei ${ }^{2}$, Essam Eldin Saeed Bedewy ${ }^{3}$ and Amr Ahmed Mahmoud Dorra ${ }^{1}$ \\ ${ }^{1}$ Internal Medicine Department, University of Alexandria \\ ${ }^{2}$ Radiodiagnosis Department, University of Alexandria \\ ${ }^{3}$ Tropical Medicine Department, University of Alexandria \\ Email:mtafifi@yahoo.com,drezzat64@yahoo.com,dr.ayman1977@gmail.com, \\ Mohamedeshafei@yahoo.com,essambedewy75@gmail.com,Amrdorrah@gmail.com
} Corresponding Author

Dr Ayman Mohamed Abdou Shamseya

Lecturer, Department of Internal Medicine, Faculty of Medicine, University of Alexandria, Egypt

Address: 21, Elsayed Radwan St, Miami, Alexandria, Egypt

Email:dr.ayman1977@gmail.com,Phone:+201222903176

\begin{abstract}
Background and aims: Egypt has the largest burden of hepatitis $C$ infection \& liver cirrhosis worldwide. Sixty percent of cirrhotic patients develop esophageal varices and thirty percent suffer variceal hemorrhage. Studying portal hemodynamics using duplex Doppler is non-invasive, reliable and relatively cheap method for evaluating portal hemodynamic changes in cirrhotic patients; also it can be used in studying the effect and prognosis of different drugs used to reduce portal hypertension. Whereas Baveno Consensus conference recommends $\beta$-blockers, banding ligation or both; the experts add that combined therapy is probably the best. Aim Of The Work: was to study portal hemodynamics in cirrhotic patients with esophageal varices admitted for band ligation with and without the administration of propranolol.

Patients And Methods: 50 patients eligible for the study (cirrhosis, esophageal varices and no contraindications for propranolol), were randomized into two groups: Group I: 25 patients on oral propranolol (non-selective $\beta$-blocker) combined with endoscopic variceal band ligation. Group II: 25 patients on endoscopic variceal band ligation alone without oral propranolol.

RESULTS: As regards to Portal vein diameter (PVD), Portal vein flow velocity (VEL), and Congestion index $(C I)$, there was no statistically significant difference between the two groups before the start of the treatment. After 6 months of treatment, there was statistically significant difference between the two studied groups as regards to PVD \& VEL, while non-statistically significant difference for $C I$.

Conclusions: both band ligation and propranolol reduced portal hemodynamic parameters, but patients on combination of both showed better results.
\end{abstract}

Key-words: portal hypertension, hepatitis, sclerotherapy 


\section{INTRODUCTION}

Egypt has extremely high prevalence of liver cirrhosis as Egypt is among the highest levels of seroprevalence of hepatitis $\mathrm{C}$ virus in the world ${ }^{[1]}$ Prevalence of HCV and consequently of liver cirrhosis in Egypt indicate uneven geographic distribution, with higher prevalence found in rural areas compared to urban settings, and in Lower Egypt compared to the rest of the country. ${ }^{[2]}$ The factors contributing to the spatial heterogeneity are not well understood, but disparity in the intensity of past PAT (parenteral antischistosomal therapy) campaigns has been proposed as a cause of the geographical variation ${ }^{\text {[3] }}$

It is now well established that HCV is a global health challenge and a leading cause of liver cirrhosis worldwide, with an estimated 130-170 million chronic infections (2-3\% of the global population). ${ }^{[4]}$

Measurement of portal hemodynamics can serve as an important tool in the follow-up of patients undergoing endoscopic and/or pharmacologic intervention for secondary prevention of variceal hemorrhage. ${ }^{\text {[5] }}$

The recommendations of the American College of Gastroenterology state that combined endoscopic and pharmacological therapy is the most effective for secondary prophylaxis ${ }^{[6]}$ Whereas the Baveno Consensus conference recommends either $\beta$-blockers, banding ligation or both; the experts add that combined therapy is probably the best treatment. ${ }^{[7]}$

The aim of this work was to study the portal hemodynamics (measured by Doppler ultrasound) in cirrhotic patients with esophageal varices admitted for band ligation with or without the administration of oral non selective beta blockers.

\section{PATIENTS AND METHODS}

The study included fifty patientsadmitted to the main university hospital of Alexandria.

\section{Inclusion criteria:}

- Diagnosis of liver cirrhosis clinically, radiologically and by liver biopsy.

- Diagnosis of esophageal varices endoscopically either bleeding or at high risk of bleeding.

\section{Exclusion criteria:}

- Contraindications to beta-blockers like asthma, uncontrolled diabetes mellitus or brady-arrhythmia, concurrent treatment with $\beta$-blockers or nitrates for other reasons, or documented malignant disease.

The patients were divided into groups as follow:

Group I: 25 patients on oral propranolol (non-selective $\beta$-blocker) $40 \mathrm{mg}$ orally daily combined with endoscopic variceal band ligation.

Group II: 25 patients on endoscopic variceal band ligation alone without oral propranolol.

\section{METHODS}

- Written consent was obtained from all patients to participate in the study.

- All patients will be subjected to the following:

(1) Doppler ultrasound for measuring portal hemodynamics at the beginning of the study.

(2) Upper gastrointestinal endoscopy for detection of esophageal varices and rubber band ligation of the varices.

(3) Repeating Doppler ultrasound after six month's period for reporting the hemodynamic changes in both groups. 


\section{RESULTS}

\section{The Portal vein diameter (PVD) before and after 6 months:}

Table (1) shows comparison between the two studied groups regarding PVD before the start of treatment and after 6 months;

There was no statistically significant difference between the two groups before the start of the treatment regarding PVD.

There was statistically significant difference between the two studied groups after treatment. ( $\mathrm{P}=0.001)$.

Generally, there was no statistically significant difference between the two groups regarding PVD at the start of the study, while there was statistically significant difference between the two studied groups after 6 months. $(\mathrm{P}=0.001)$

\section{Portal vein flow velocity (VEL) before and after 6 months:}

Table (2) shows comparison between the two studied groups regarding VEL before the start of treatment and after 6 months;

There was no statistically significant difference between the two groups before the start of the treatment regarding VEL.

There was statistically significant difference between the two studied groups after treatment. ( $\mathrm{P}=0.001)$.

Generally, there was no statistically significant difference between the two groups regarding VEL before the start of treatment, while there was statistically significant difference between the two studied groups after 6 months treatment. $(\mathrm{P}=0.001)$

\section{Portal flow in L/min before and after 6 months}

Table (3) shows comparison between the two studied groups regarding flow in L/min before the start of treatment and after 6 months;

There was no statistically significant difference between the two groups before the start of the treatment regarding portal flow.

There was statistically significant difference between the two studied groups after treatment. $(\mathrm{P}=0.034)$.

Generally, there was no statistically significant difference between the two groups regarding flow before treatment, while there was statistically significant difference between the two studied groups after 6 months. $(\mathrm{P}=0.034)$

\section{Congestion index (CI) before and after 6 months}

Table (4) shows comparison between the two studied groups regarding CI before treatment and after 6 months;

There was no statistically significant difference between the two groups before the start of the treatment regarding CI.

There was no statistically significant difference between the two studied groups. $(\mathrm{P}=0.436)$.

Generally, there was no statistically significant difference between the two groups in CI before and after 6 months. 


\section{JMSCR VoI||3||Issue||10||Page 8008-8015||October}

Table (1): Comparison between the two studied groups regarding PVD before the start of treatment and after 6 months

\begin{tabular}{||l|l|l|l||}
\hline & \multicolumn{2}{|l||}{ PVD (Cm) } & \multirow{2}{*||}{} \\
\cline { 2 - 3 } & Before & After & \\
\hline Group (I) combined & & & \\
Range & $1.330-1.600$ & $1.208-1.453$ & $0.01^{*}$ \\
Mean & 1.481 & 1.345 & \\
SD & 0.077 & 0.070 & \\
\hline Group (II) EVL alone & & & \\
Range & $1.300-1.600$ & $1.284-1.581$ & 0.237 \\
Mean & 1.442 & 1.425 & \\
SD & 0.084 & 0.083 & \\
\hline P & 0.064 & $0.001^{*}$ & \\
\hline \hline
\end{tabular}

Table (2): Comparison between the two studied groups regarding VEL $(\mathrm{cm} / \mathrm{sec})$ before the start of treatment and after 6 months

\begin{tabular}{||l|l|l|l||}
\hline \multirow{2}{*}{ Group (I) combined } & \multicolumn{2}{|l||}{ Mean VEL $(\mathbf{c m} / \mathbf{s e c})$} & \multirow{2}{*}{ P } \\
\cline { 2 - 3 } & Before & After & \\
Range & & & \\
Mean & $7-10.8$ & $6.342-9.7848$ & \multirow{2}{*}{$0.002^{*}$} \\
SD & 8.894 & 8.058 & \\
\hline Group (II) EVL alone & 1.009 & 0.914 & \\
Range & & & \multirow{2}{*}{0.182} \\
Mean & $8-10.3$ & $7.84-10.094$ & \\
SD & 8.962 & 8.783 & \\
\hline P & 0.683 & 0.670 & \\
\hline \hline
\end{tabular}

Table (3): Comparison between the two studied groups regarding portal flow before the start of treatment and after 6 months

\begin{tabular}{|c|c|c|c|}
\hline & \multicolumn{2}{|c|}{ Flow (L/min) } & \multirow[t]{2}{*}{$\mathbf{P}$} \\
\hline & Before & After & \\
\hline \multicolumn{4}{|l|}{ Group (I) combined } \\
\hline Range & $0.771-1.00$ & $0.698-0.905$ & \multirow{3}{*}{$0.001 *$} \\
\hline Mean & 0.913 & 0.826 & \\
\hline SD & 0.054 & 0.049 & \\
\hline \multicolumn{4}{|l|}{ Group (II) EVL alone } \\
\hline Range & $0.703-1.00$ & $0.688-0.984$ & \multirow{4}{*}{0.170} \\
\hline Mean & 0.876 & 0.856 & \\
\hline SD & 0.070 & 0.068 & \\
\hline $\mathbf{P}$ & 0.059 & $0.034 *$ & \\
\hline
\end{tabular}


Table (4): Comparison between the two studied groups regarding CI before the start of treatment and after 6 months

\begin{tabular}{|l|l|l|l||}
\hline \multirow{2}{*}{} & \multicolumn{2}{|l|}{ CI } & \multirow{2}{*}{ P } \\
\cline { 2 - 3 } & Before & After & \\
\hline Group (I) combined & & $0.121-0.237$ & \multirow{2}{*}{$0.046^{*}$} \\
Range & $0.134-0.262$ & 0.180 & \\
Mean & 0.198 & 0.036 & \\
\hline Group (II) EVL alone & 0.040 & & \multirow{2}{*}{0.339} \\
Range & $0.1288-0.2480$ & $0.126-0.242$ & \\
Mean & 0.185 & 0.181 & \\
SD & 0.033 & 0.032 & \\
\hline $\mathbf{P}$ & 0.095 & 0.436 & \\
\hline
\end{tabular}

\section{DISCUSSION}

The present study aimed to compare between patients with band ligated varices who receive propranolol and others who don't receive the drug by using parameters of portal hemodynamics.

The present study showed better hemodynamic response regarding portal diameter, portal flow, flow velocity, and congestion index in the group of patients who received combination therapy than those who were treated by EVL alone. Sarin, et al ${ }^{[8]}(2005)$ in their study on one hundred and forty-four high-risk varices patients compared endoscopic variceal ligation (EVL) with propranolol and EVL alone in the prevention of first variceal bleed. They concluded that Both EVL plus propranolol and EVL alone are effective in primary prophylaxis of bleeding from high-risk varices however the recurrence of varices is lower if propranolol is added to EVL.

Ravipati et al. ${ }^{[9]}$ (2009) compared the efficacy of endoscopic procedures with that of pharmacotherapy in the prevention of mortality and rebleeding in a met-analysis including Twenty-five clinical trials with a total of 2159 patients. They concluded that Pharmacotherapy may be as effective as endoscopic therapy in reducing rebleeding rates and all-cause mortality. Pharmacotherapy plus endoscopic intervention is more effective than endoscopic intervention alone.

In the present study there was significant reduction in portal flow velocity in the group of patients received combination therapy. In agreement with these results Tincani et al. studied the Effect of propranolol $40 \mathrm{mg}$ on portal hemodynamics measured by duplex Doppler ultrasonography; they found that Propranolol induced a significant reduction in maximum portal flow velocity. ${ }^{[10]}$

In the present study, the use of the combination between Propranolol and EVL decreased the portal pressure. In agreement with this, Villanueva, et al ${ }^{[11]}$ studied the hemodynamic response of cirrhotic patients with oesophageal varices receiving a combination of beta-blockers (nadolol) and EVL by measuring HVPG at baseline and after four weeks they found that the combined therapy nadolol + EVL, decreased the HVPG significantly, with a mean reduction of $12-21 \%$.In agreement with the present study, Ana-Maria et

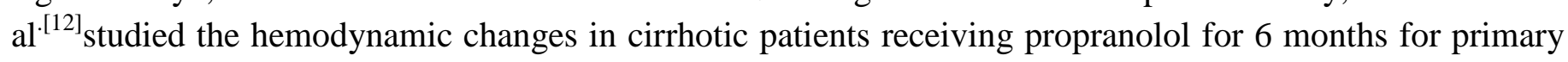
prophylaxis of variceal bleeding by using Doppler ultrasonography in day one and then after about 6 months. They found that the values of the portal hemodynamic parameters (PFV, PVD and CI) decreased about 9\%. In agreement with the present study, Ahmad Abdel Bary et al ${ }^{[13]}$ (2012) studied the effect of varying doses of Propranolol on portal hemodynamics for a period of only one week using duplex Doppler ultrasonography for measuring of portal vein diameter (PVD), mean velocity $\left(\mathrm{V}_{\text {mean }}\right)$, portal flow volume 
(PFV) and congestion index (CI). They found that Propranolol in different doses reduced all the mentioned portal hemodynamic parameters. But doses of $30 \mathrm{mg}$ and $60 \mathrm{mg}$ used daily for one week showed no significant differences. However, Propranolol in a dose of $90 \mathrm{mg}$ daily for the same period showed significant change in PFV and $\mathrm{V}_{\text {mean. }}$. In agreement with the present study, Zain-Hamid et al. ${ }^{[14]}$ (2003) studied The effectiveness of propranolol in prevention of variceal hemorrhage in post-hepatitis cirrhotic patients by using duplex Doppler ultrasonography in assessing the different portal hemodynamics parameters, mean blood flow velocity $\left(\mathrm{V}_{\text {mean }}\right)$ and diameter of portal vein (PVD), portal flow volume (PFV) and congestion index (CI) of the portal system were assessed at baseline and after one week. They compared the mentioned hemodynamic parameters in different daily doses (30,60 and $90 \mathrm{mg}$ ) taken for a week, they found that the portal flow velocity decreased in the three different doses, with more reduction of portal velocity with increasing the dosage. According to their study they concluded that in Malaysian patients a dose of $60 \mathrm{mg} /$ day can achieve a good hemodynamic response with better tolerability.

In the present study, the portal flow velocity (VEL) reduced in both groups; there was no statistical significant difference between the two groups in (VEL) before the start of treatment, while there was statistical significant difference between the two studied groups after the 6 months in favor of the group of patients received combined therapy. Also, regarding the portal flow there was a reduction in both groups, there was no statistical significant difference between the two groups regarding the Portal flow before treatment, while there was statistical significant difference between the two studied groups after 6 months in favor of the group of patients received combined therapy. In agreement with this study, Rebecca McKay, et $\mathrm{al}^{[15]}$ (2007)compared three groups of liver cirrhosis patients who had esophageal varices by using Doppler on the portal vein using different modalities of treatment (propranolol plus band ligation, band ligation alone and band ligation plus isosorbide mononitrate), they found that there was no statistically significant difference between the three studied groups regarding portal vein flow velocity before and after 6 months. However, when Tincani et al ${ }^{[10]}$ studied the effect of propranolol on cirrhotic patients with high risk of esophageal bleeding using duplex-Doppler ultrasonography they found that Propranolol caused a significant reduction in maximum portal flow velocity $(\mathrm{P}<0.001)$. Quantitative measurement of flow in the portal vein demonstrated that the velocity is reduced, to a greater or lesser degree, in cirrhotic patients in comparison with healthy subjects, and that a progressive fall in portal flow velocity would seem to be of the natural history of portal hypertension in cirrhotic patients.

Shi Minet al. (2005) approved the value of measuring portal hemodynamics and stated that Portal blood flow velocity is a good parameter to reflect the portal pressure gradient and useful for the diagnosis of portal hypertension. Therefore, the portal hemodynamics is very helpful in the assessment of the real status of cirrhosis, and should be proposed for cirrhosis staging. ${ }^{[16]}$

Regarding the congestion index (CI), Moriyasu, et al ${ }^{[17]}$ (1986) in their study that compared the portal hemodynamics by using duplex Doppler system suggested the importance of the congestion index in reflecting the pathophysiological hemodynamics of the portal venous system in portal hypertension.

In the present study, there was no statistically significant difference between the two studied groups regarding PVD at baseline and after 6 months, while there was statistically significant difference between them regarding the EVL at the start of the study and after 6 months. Shi Minet al. ${ }^{[16]}$ demonstrated no statistical difference in portal flow velocity and volume between patients with mild and severe esophageal varices, indicating that the mechanisms of varices in cirrhosis are very complicated. They are not only the consequences of high portal pressure but also of formation of regional collaterals.

Studies done to correlate between the CI and the HVPG stated that the CI is significantly correlated with HVPG values. Moriyasu et al ${ }^{[17]}$ in their study about the portal congestion index (PCI) concluded that the sensitivity of CI for detection of cirrhosis was $67 \%$ which is relatively high in comparison with portal vein 
flow velocity (23\%) and blood flow volume (60\%).Huang et al. ${ }^{[18]}$ found that PCI was significantly higher in cirrhotic patients with portal hypertension than in healthy subjects. Kayacetin et al. ${ }^{[19]}$ demonstrated significant increase in the PCI in cirrhotic patients than normal subjects, and in patients with child C cirrhosis as compared to patients with child A cirrhosis. They concluded that the decreased blood flow velocity and increased congestion index in the portal vein are related to the impairment of liver function in cirrhotic patients, and that patients with severe liver disease had lower PFV and higher PCI than patients with less severe liver disease. Abdel Motelb. ${ }^{[20]}$ Reported more elevation of PCI in patients with history of bleeding and higher grades of varices than patients without history of bleeding and lesser grades of varices. Also, Kayacetin et al. ${ }^{[19]}$ reported that cirrhotic patients with large varices had higher PCI than those without varices. This is possibly due to the opening up of many spontaneous portosystemic shunts and collaterals, which may decompress the portal system in patient with both small and large varices. There was no significant difference in PCI between patients with and without history of EVL.

The study concluded that both band ligation and propranolol reduced portal hemodynamic parameters, but patients on combination of both showed better results as regardsto Portal vein diameter (PVD), Portal vein flow velocity (VEL), and Congestion index (CI).

\section{REFERENCES}

1. Frank C, Mohamed MK, Strickland GT, et al. The role of parenteral antischistosomal therapy in the spread of hepatitis C virus in Egypt. Lancet 2000; 355: 887-91.

2. Breban R, Doss W, Esmat G, et al. Towards realistic estimates of HCV incidence in Egypt. J Viral Hepat 2013;20:294-296.

3. Mohamoud Y, Mumtaz G, Riome S, Miller D, Abu-Raddad L. The epidemiology of hepatitis C virus in Egypt: a systematic review and data synthesis. BMC Infect Dis 2013;13:288.

4. WHO. Hepatitis C Fact sheet 164. (Online at:http://www.who.int/mediacentre/factsheets/fs 164/en/) 2014.

5. Walid S. Ayoub. Combination of pharmacologic and endoscopic therapy or the secondary prevention of esophageal variceal bleeding. Gastrointestinal endoscopy 2009; 70:665-7.

6. Garcia-Tsao G, Sanyal AJ, Grace ND, et al. Prevention and management $\mathrm{f}$ gastroesophageal varices and variceal hemorrhage in cirrhosis. Am J Gastroenterol 2007; 102: 2086-102.

7. De Franchis R. Evolving consensus in portal hypertension. Report of the Baveno IV consensus workshop on methodology of diagnosis and therapy in portal hypertension. J Hepatol 2005; 43: $167-$ 76

8. Sarin SK, Wadhawan M, Agarwal SR, Tyagi P, Sharma BC. Endoscopic variceal ligation plus propranolol versus endoscopic variceal ligation alone in primary prophylaxis of variceal bleeding. Am J Gastroenterol. 2005 Apr; 100(4):797-804.

9. Ravipati M, Katragadda S, Swaminathan PD, Molnar J, Zarling E. Pharmacotherapy plus endoscopic intervention is more effective than pharmacotherapy or endoscopy alone in the secondary prevention of esophageal variceal bleeding: a meta-analysis of randomized, controlled trials. Gastrointest Endosc. 2009 Oct; 70(4):658-664.e5.

10. Tincani E, Cioni G, D'Alimonte P, et al. Effects of propranolol compared with clonidine on portal haemodynamics: a double-blind cross-over study using duplex-Doppler ultrasonography. Eur J Gastroenterol Hepatol. 1995 Sep; 7(9):893-7.

11. Villanueva C, Aracil C. Gastrointestinal Bleeding Unit, Department of Gastroenterology, Hospital de la Santa Creu I Sant Pau, Autonomous University, Barcelona, Spain. Aliment Pharmacol Ther Journal compilation 2009; 29: 397-408. 
12. Ana-Maria et al. Hemodynamic changes in cirrhotic patients receiving propranolol. Romanian Journal of gastroenterology. 2005; 14(2): 123-127.

13. Ahmad Abdel Bary, Riham Mohamed Elshafie, Heba Mohamed Abdella, et al. Evaluation of the effect of Propranolol on portal hemodynamics in patients with HCV-related Cirrhosis. Journal of American Science 2012; 8(3):447-456.

14. Zain-Hamid R, Ismail Z, Mahendra Raj, et al. The effect of propranolol in Malay patients with liver cirrhosis - a pharmacodynamic evaluation. Malaysian Journal of Medical Sciences 2003; 10(1):6573.

15. McKay, Rebecca, and Nigel R. Webster. "VARICEAL BLEEDING." Continuing Education in Anaesthesia, Critical Care and Pain 2007 ;(7): 6.

16. Shi Min B, Yan XW, Mu Ling Q, Wu Huang T, XU J. Value of portal hemodynamics and hypersplenism in cirrhosis staging. World J Gastroeneterol 2005; 11(5): 708-11.

17. Moriyasu F, Nishida O, Ban N, Nakamura T, Sakai M, MiyakeT, Uchino H. Congestion index of the portal vein. AJR 1986; 146: 735-9.

18. Huang J, Yin X, Lu M, Chen J, et al. Portal hemodynamics in cirrhotics with portal hypertension using color Doppler velocity profile. Chin Med J (Engl) 1999; 112(7): 627-31.

19. Kayacetin E, Efe D, Dogan C. Portal and splenic hemodynamics in cirrhotic patients: relationship between esophageal variceal bleeding and the severity of hepatic failure. J Gastroenterol 2004; 39 : 129- 667.

20. Abdel-Motelb M. et al. Effect of repeated large volume paracentesis on portal hemodynamics and risk of bleeding in patients with mixed liver cirrhosis and tense ascites. Ms Thesis, Faculty of Medicine, Alex Univ. 2002. 